\title{
PROCESSO SUCESSÓRIO EM PROPRIEDADES RURAIS NA REGIÃO OESTE DE SANTA CATARINA
}

\author{
Cesar Augustus WINCK ${ }^{1, *}$ \\ Sandra DALLA PASQUA ${ }^{2}$ \\ Augusto FISCHER ${ }^{3}$ \\ Miguelangelo Gianezini ${ }^{4}$
}

\author{
${ }^{1}$ Dr. em Agronegócios. Professor do Mestrado Profissional em Administração da Universidade do Oeste de Santa Catarina \\ - UNOESC. \\ ${ }^{2}$ Estudante de Agronomia da Universidade do Oeste de Santa Catarina - UNOESC \\ ${ }^{3}$ Dr. em Administração. Professor do Mestrado Profissional em Administração da Universidade do Oeste de Santa Catarina \\ - UNOESC \\ ${ }^{4}$ Dr. em Agronegócios. Professor da Universidade do Estremo Sul de Santa Catarina - UNESC \\ *Autor correspondente: cesar.winck@unoesc.edu.br
}

Recebido em: 12/09/2013 - Aprovado em: 14/12/2013 - Disponibilizado em: 15/01/2014

RESUMO: A sucessão rural na atualidade é uns dos principais problemas enfrentados pela agricultura familiar, principalmente pelo desinteresse dos filhos dos produtores em assumirem as atividades produtivas da família. O objetivo desta pesquisa foi analisar a realidade do processo sucessório na atualidade e possíveis fatores que motivam a permanência ou exclusão do jovem nas propriedades rurais da Região Oeste de Santa Catarina. O procedimento metodológico adotado foi uma pesquisa bibliográfica associada à aplicação de questionários estruturados a 115 produtores de 12 municípios da região. Observou-se que a maioria das propriedades não possui um sucessor interessado, embora haja interesse por parte dos proprietários atuais, na perpetuação da atividade agrícola familiar.

Palavras-chave: Sucessão, Gestão, Agricultura familiar, Pequenos produtores.

ABSTRACT: The succession rural nowadays is one of the main problems faced by family agriculture, mostly in disinterestedness of the children of farmers in taking up productive activities of the family. The aim of this research was to analyze the reality of the succession process at the present time and possible factors that motivate the permanence or exclusion of the young in the farms of the Western Region of Santa Catarina State, in south of Brazil. The methodological approach adopted was a bibliographic research associated with structured questionnaires applied to 115 producers in 12 municipalities. It was observed that most of the properties do not have a successor interested, although there is interest by current owners, in perpetuating the family farming activity.

Keywords: Succession, Management, Family farming, Smallholders.

\section{INTRODUÇÃO}

Santa Catarina destaca-se entre os principais estados brasileiros produtores de alimentos, apresentando elevados índices de produtividade por área, utilização de tecnologia e características de produção familiar, em mais de $90 \%$ das propriedades rurais. O setor agropecuário representa 12,8\% do PIB estadual, e considerando-se todas as atividades do agronegócio, a contribuição ao PIB estadual ultrapassa os 20\% (CEPA, 2011).

Dentre os produtos agropecuários de maior relevância econômica para o Estado, destaca-se o leite que apresenta em sua 
composição: proteínas, vitaminas, gordura, lactose, carboidratos e sais minerais (principalmente cálcio) (OLIVEIRA et al., 1999; MULLER, 2002; COSTA, 2003).

A agricultura familiar é responsável por grande parte da produção de alimentos do Estado e país, ocupando a maioria da população rural trabalhadora (MDA, 2009) Apesar de sua expressividade, a partir de 1990 os estabelecimentos familiares perderam continuamente e por diversos motivos, seus sucessores naturais, com a saída dos jovens do meio rural em direção as cidades (MENDONÇA et al., 2008).

O Oeste Catarinense, com 1,2 milhão de habitantes, dos quais 340 mil residentes no meio rural, caracteriza-se pelo predomínio da agricultura familiar diversificada, voltada ao mercado e integrada à agroindústria (CEPA, 2011). Estes dados tornam-se relevantes ao comparar a região, que possui $28 \%$ de sua população no meio rural, enquanto a média brasileira é de $16 \%$.

Neste contexto, a região do Oeste catarinense caracteriza-se por sua forte indústria agroalimentar, alicerçada historicamente na agricultura familiar, tendo constituído o maior cluster agroindustrial de aves e suínos do país e posição expressiva na produção láctea nacional. $\mathrm{O}$ modelo da agricultura familiar diversificada, voltada ao mercado e associada à agroindústria serviu de base histórica para o crescimento econômico da região (PLEIN, 2005), sendo articulado pelo Estado, pelo setor agroindustrial e pelo segmento dos agricultores familiares (FERRARI, 2003).

Considerando que a região Oeste destaca-se no setor leiteiro catarinense e que esta produção advém fundamentalmente da pequena propriedade rural e explorada em regime familiar, buscou-se identificar através de pesquisa aplicada, a realidade do processo sucessório na atualidade e alguns possíveis fatores que motivam a permanência ou saída dos jovens nas propriedades.

\section{A AGRICULTURA FAMILIAR}

A expressão "agricultura familiar" vem ganhando legitimidade social e científica no Brasil, sendo utilizada frequentemente pelos movimentos sociais rurais, órgãos governamentais e pesquisadores de diversas áreas, que se ocupam da agricultura e do mundo rural (SCHNEIDER, 2005).

Segundo Bianchi e Orlowski (2011), a agricultura familiar refere-se a um grupo social que compartilha um mesmo espaço (não necessariamente uma habitação comum) e possui em comum a propriedade de um pedaço de terra para cultivo agrícola, sendo que possuem laços de parentesco. É no âmbito familiar que se discute e se organiza a inserção produtiva, laboral, social e moral de seus integrantes, e é em função desse referencial que se estabelecem as estratégias individuais e 
coletivas que visam garantir a reprodução do grupo.

\subsection{A AGRICULTURA FAMILIAR EM} SANTA CATARINA

O Estado de Santa Catarina dispõe de um patrimônio natural rico e diverso, que contribuiu para moldar sua estrutura fundiária, caracterizada pela predominância de um modelo de agricultura familiar, ou seja, de pequenas propriedades (CEPA, 2011).

Com base nos critérios de classificação do Programa Nacional da Agricultura Familiar (Pronaf), estima-se que a agricultura familiar em Santa Catarina representa um universo de 180 mil famílias, ou seja, mais de $90 \%$ da população rural. Estas famílias de agricultores, apesar de ocuparem apenas $41 \%$ da área dos estabelecimentos agrícolas, são responsáveis por mais de $70 \%$ do valor da produção agrícola e pesqueira do Estado, destacando-se na produção de $67 \%$ do feijão, $70 \%$ do milho, $80 \%$ dos suínos e aves, $83 \%$ do leite e $91 \%$ da cebola (CEPA, 2011).

Além desses produtos, é grande a participação da agricultura familiar na produção de mel, arroz, batata, fumo, mandioca, tomate, banana e uma grande variedade de outros hortigranjeiros e frutas. Também tem no setor florestal importante base econômica.

O setor primário é preponderante na região Oeste, sendo a principal região de produção agroalimentar de Santa Catarina, e onde a maioria dos municípios ainda mantém sua base produtiva assentada no meio rural. Quando se analisa a distribuição populacional na região Oeste de Santa Catarina percebe-se que predominam os municípios de pequeno porte, sendo que, dos 110 municípios desta região, metade possui população menor que 5.000 habitantes, sendo que estes municípios só representam $15 \%$ do total populacional (ALVES e MATTEI, 2006).

Neste contexto a produção leiteira está geograficamente distribuída em quase todo o território catarinense, contribuindo de maneira significativa para a manutenção de produtores no campo e, consequentemente, para redução do êxodo rural em várias regiões, principalmente de pequenos agricultores (MELLO e FERRARI, 2003).

\subsection{PROCESSO SUCESSÓRIO}

O processo sucessório é o rito de transferência de poder e de capital entre a geração que atualmente dirige e a que virá a dirigir determinada organização. $\mathrm{Da}$ mesma forma acontece nas empresas familiares, sendo um processo lento e gradual, variando de família para família, sendo que quanto mais cedo for realizado, melhor para os integrantes (CARVALHO, 2007; ALHERT, 2009).

A sucessão é um processo formado por três componentes: a transferência patrimonial, a continuação da atividade profissional paterna e a retirada das gerações mais velhas do comando 
do negócio (LEONE, 1991; SILVESTRO et al., 2001; ABRAMOVAY, 2001).

A questão de sucessão dentro das empresas familiares apresenta-se bastante conflitante, pois existe a resistência por parte dos fundadores em deixar o comando da empresa para o filho ou para aquele que se encontra mais apto a comandar o empreendimento. Isso geralmente ocorre porque o fundador não percebe que o filho ou a nova geração passou por um processo de ensino, no qual aprendeu a base para comandar ou até mesmo a montar a sua própria organização, já que o modo de criação das duas gerações foi totalmente diferente (JUCHEM; BOSCARIN; CÉSPEDES, 2006).

No Brasil, a taxa de escolarização é melhor para a população da zona urbana do que para a da zona rural (CEPA, 2011). Jovens que possuem baixo nível de formação educacional julgam ter melhores oportunidades apenas no meio rural. Para Abramovay (2000) é entre os rapazes que se encontra a maior parcela dos que não tiveram acesso à educação, sendo os prováveis para permanência na propriedade.

Os jovens deixam a escola, pois muitas vezes precisam complementar a renda familiar, abandonando temporariamente, para ajudar os pais no plantio quando chega o período de chuvas, ou porque acham que a escola não thes fornece perspectivas de futuro profissional (SILVA, 2002).
A baixa remuneração da agricultura é apontada por Ferrari (2003) como uma força de expulsão e fator de esvaziamento do meio rural. Evidente que o porte econômico do estabelecimento pode definir ou não a presença de um sucessor. Entretanto, diferente dos assalariados, a posse de uma propriedade, mesmo de pequeno porte, permite à família viver, ou pelo menos sobreviver.

A consequência deste quadro de crise é o empobrecimento da população rural, o despovoamento de muitas localidades e o envelhecimento da população, o que pode criar fortes barreiras à promoção de um desenvolvimento rural, cujos resultados sejam equitativos socialmente e equilibrado geograficamente (MELLO, 2006).

Nas gerações passadas, a situação predominante era de se estimular todos os filhos a serem agricultores. $\mathrm{Na}$ atual geração predomina a não interferência nas decisões profissionais dos filhos, e sendo assim, aumentaram as situações de desestímulo por parte dos filhos, passando de 3,4\% para $19,6 \%$, os que consideram a agricultura uma atividade desestimulante (CARVALHO, 2007).

Segundo Carvalho (2007), mesmo os pais adotando a decisão de não se posicionarem sobre a permanência dos filhos nas atividades da propriedade, deixando os jovens livres para decidirem sobre seu futuro, acabam por perceber que isto já não é mais uma questão de escolha, mas sim, acabam por julgar que este 
seja seu destino, ou seja, acreditam que não possuem outra escolha, pois não possuem estudo suficiente e só sabem realizar atividades ligadas a produção agropecuária.

A rejeição pela profissão agrícola é muito maior entre as moças, sendo que para muitas delas, o futuro desejado é morar e trabalhar na cidade. Para os rapazes, poucos julgam que na cidade encontraram a realização profissional almejada, e além do mais, é entre os rapazes que se encontra a maior parcela dos que não tiveram acesso à educação (ABRAMOVAY, 2000).

Os filhos das famílias de maior renda encaram a permanência na agricultura como promissora, e isto é nítido, tanto entre rapazes como entre as moças, porém como possuem maiores oportunidades, existem grandes chances de acabarem deixando para traz a agricultura e irem em busca de outros sonhos profissionais ou até mesmo pessoais (ABRAMOVAY, 2000).

O planejamento e discussão da sucessão não acontece na maioria das propriedades familiares rurais. A transferência das propriedades acaba ocorrendo através de doação a um ou mais filhos, sendo selado o compromisso com estes sucessores, de cuidarem dos pais até o fim da vida (AHLERT, 2009).

Para Lodi (1998), o planejamento do processo sucessório deve iniciar o mais cedo possível e debatê-lo muito bem. O fundador deve resolver sua sucessão enquanto ainda estiver no comando (MARTINS et al., 1999), para que o processo sucessório não seja resolvido judicialmente, quando o proprietário falecer (AHLERT, 2009).

A empresa rural precisa produzir; gerar emprego, renda e resultados; para que desta forma, possam acontecer os investimentos necessários, e com isto, possibilitar que as futuras gerações continuem o trabalho. Precisase criar a perspectiva de que o jovem tem um negócio na mão e só dependerá do próprio trabalho para obter sucesso (ELY, 2003). Esta motivação precisa acontecer, pois somente assim ele poderá profissionalizar o negócio, buscar parcerias, desenvolver novos produtos, gerando com isso, resultado a todos os envolvidos.

Desde 1990 no sul do país, os estabelecimentos agrícolas familiares estão perdendo seus sucessores com a saída dos jovens do meio rural. As principais causas para este esvaziamento são: acesso a melhores condições de estudo, insatisfação com o ganho obtido na agricultura e a imagem negativa do trabalho agrícola (WEISHEIMER, 2005; MENDONÇA et al., 2008)

Em Santa Catarina, mais especificamente na região Oeste, a permanência na profissão dos pais pela maioria dos filhos de agricultores, é desejada. Porém há muitos obstáculos para esta realização (ABRAMOVAY, 2000). Entre os principais 
fatores que dificultam a continuação na profissão estão: falta de capital para investimentos, falta de novas oportunidades e falta de terra suficiente para o cultivo de forma rentável.

\subsection{A SUCESSÃO RURAL NO OESTE DE} SANTA CATARINA

A agricultura familiar do Oeste de Santa Catarina começa a enfrentar problemas sucessórios que não existiam até pouco tempo atrás. Enquanto no passado os filhos de agricultores apresentavam forte desejo em permanecer na agricultura e a família elaborava estratégias para que isto se concretizasse, hoje os rapazes com menos de 20 anos e, sobretudo as moças, rejeitam esta ideia (MELLO, 2006). Preferem a vida urbana, os horários fixos e as rendas regulares do trabalho assalariado a desenvolver atividades agrícolas que lhes parecem mal remuneradas e penosas.

$\mathrm{O}$ modelo agroindustrial regional que historicamente serviu de base para o desenvolvimento da região, começa a revelar os distintos interesses dos diversos atores sociais em relação ao desenvolvimento regional e a agricultura familiar, implicando na necessidade da construção de um novo modelo de desenvolvimento que incorpore as preocupações com a sustentabilidade e equidade social (FERRARI, 2003).

Além disso, existem outras preocupações que estão relacionadas a viabilidade econômica e mais recentemente da questão da sucessão na gestão das propriedades rurais. Neste contexto a condição atual da agricultura familiar do Oeste catarinense revela uma crise de sucessão - haja vista as aspirações que os pais almejam para os seus filhos e filhas - que tem contribuído para que, desde cedo os filhos comecem a construir seu futuro voltado para o meio urbano.

Esta condição acentua-se ainda mais quando é observada a questão de gênero. Segundo Silvestro et al. (2001), em muitos casos os próprios pais estimulam, de forma explícita ou velada à saída das filhas rumo à construção de uma vida profissional fora da agricultura. Neste caso, a crise de reprodução da agricultura familiar pode ser o próprio reflexo de uma crise de identidade, isto é, da negação da condição de colono.

Para que um produtor rural possa reproduzir-se como tal e formar sucessores, é necessário que ele julgue que sua vida de agricultor ainda mereça ser vivida e que seus filhos acreditem nisso. Contudo, é exatamente o estilo de vida (colono) dos pais que tende a ser rejeitada pelos filhos/filhas (MELLO, 2006).

Por conseguinte, os filhos(as) de agricultores buscam fora da agricultura e do meio rural, oportunidades de trabalho que atendam suas aspirações pessoais, seja no campo profissional, econômico, cultural ou social. Essa perda de identidade, ou o desejo de se afastar do estigma de ser colono, faz com 
que até mesmo o trabalho assalariado, que no passado era avaliado negativamente pelos agricultores familiares, passa a ser reavaliado e considerado, como observou Renk (2000), como uma condição privilegiada: trabalhar na sombra; ter segurança, expressa no rendimento mensal; ter férias anuais e folga semanal. Hoje migrar para esses jovens significa dizer que "não vale mais a pena ser colono" e, em certo sentido, recusar à condição de agricultor.

Todo este contexto depende também da manutenção dos agricultores na produção, sejam eles produtores de porte pequeno, médio ou grande. Não se concebe a exclusão destes por falhas na produção, sejam elas de origem higiênica, microbiológica ou sanitária, visto que parcela significativa da renda mensal de grande parte dos agricultores catarinenses provém da produção de leite, além da produção para a subsistência da família rural (BODENMÜLLER et al., 2010).

Segundo Montoya e Finamore (2010), quanto à sucessão na gestão da atividade leiteira, em média, 58,08\% dos produtores acreditam que os filhos continuarão com o gado de leite, e $23,74 \%$ acham que os filhos deixarão o meio rural, migrando para a cidade, e 3,03\% dos jovens trocarão de atividade e/ou venderão a propriedade. Em conjunto, as informações sugerem que, quanto menor for à escala de produção de leite, menor será a rentabilidade e, portanto, o processo de sucessão mais incerto. Ainda segundo Montoya e Finamore (2010), entre os entrevistados, 78,28\% afirmam que dentre as atividades que realizam em suas propriedades, a pecuária de leite é a mais importante, sendo que em 70,83\% dos casos, é a esposa que trabalha na produção do leite, realizando a ordenha, o manejo do rebanho e o controle de receitas e despesas, reduzindo ainda mais o custo de produção.

\section{METODOLOGIA}

O estudo foi realizado em 12 municípios da região Oeste do Estado de Santa Catarina, através da aplicação de questionário estruturado a 115 produtores de leite, no período de maio e junho de 2012, seguindo metodologia descrita por Haguette (1990) e Thiollent (1996) e fundamentado por revisão bibliográfica e documental.

Os dados coletados através da aplicação dos questionários foram processados pelo programa SPHINX@, pacote estatístico para análise de resultados de entrevistas e estudos quantitativos e qualitativos.

\section{RESULTADOS E DISCUSSÃO}

A sucessão nas propriedades rurais pesquisadas pode ser considerada um problema a ser enfrentado em breve, pois $55,6 \%$ não possuem algum familiar para proceder à continuidade das atividades produtivas. Para compreender esta questão complexa, é preciso ter presente três aspectos: a transferência do patrimônio, a continuidade da atividade 
profissional e a saída da geração paterna do comando (ABRAMOVAY, 2001) e estes aspectos são identificados de forma clara na região estudada.

Após levantamento de dados de 115 produtores da Região Oeste de Santa Catarina, e em doze municípios diferentes, chegou-se a uma área média por propriedade de 27,4 ha, com idade média de 48 anos entre os produtores. As atividades principais destas propriedades eram o leite $(47,8 \%)$, seguido do milho $(15,6 \%)$, soja $(7,8 \%)$, suínos $(8,6 \%)$, aves $(6,1 \%)$ e outras atividades como hortaliças, frutas, alfafa e bovinos de corte $(13,6 \%)$.

O perfil das propriedades leiteiras do Oeste de Santa Catarina baseia-se no modelo de agricultura familiar, ou seja, em pequenas propriedades com mão de obra da própria família. A produção diária de leite identificada nas entrevistas foi de 250 litros na média, sendo a menor produção com 25 litros/dia e a maior com 1100 litros/dia. Sendo assim, o leite é responsável por parcela significativa da renda mensal dos produtores rurais, e a cadeia produtiva do leite gera milhares de empregos diretos e indiretos para a economia catarinense (MELLO e FERRARI, 2003).

Quando perguntados quanto à satisfação com a atividade agrícola (Figura 1), aproximadamente $\quad 78 \%$ disseram estar satisfeitos e o restante se declarou insatisfeitos ou indiferentes com a questão. Segundo os próprios produtores, a satisfação com a atividade agrícola, depende da renda mensal gerada, do gosto individual pela produção e da tradição familiar na produção rural, mesmo sabendo-se da possível desvalorização de seu trabalho pela sociedade.

Figura 1: Satisfação dos produtores rurais com a atividade agrícola.

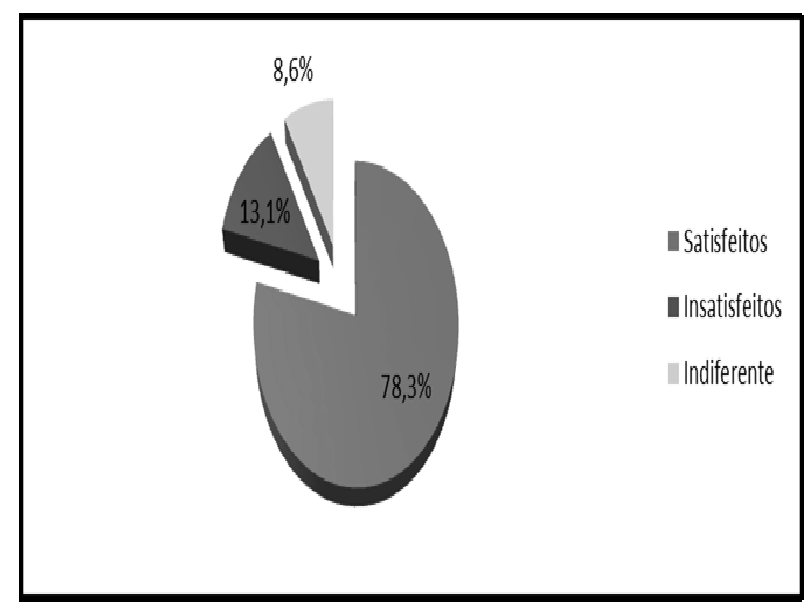

Fonte: Dados da pesquisa (2012).

Considerando que a agricultura do Oeste catarinense está baseada em sua maioria por pequenos produtores, quando os entrevistados eram indagados sobre a existência de algum interessado em continuar com a produção, obteve-se um total de $55,6 \%$ de propriedades sem um possível interessado e 38,3\% com descendentes diretos demonstrando interesse pela continuidade da produção.

Quando questionados sobre o motivo por não haver interessados na continuidade da atividade agrícola, 45,2\% declararam que os filhos(as) estavam encaminhados financeiramente na cidade e $25,7 \%$ disseram que não tinham filhos. 
Observou-se que os descendentes de famílias rurais com maior volume de produção agrícola e consequente maior renda, optam com maior facilidade pela permanência na agricultura, conseguindo assim vislumbrar nesta atividade, um futuro promissor.

O processo sucessório tende a ser um momento complicado, tanto em empresas urbanas, quanto em propriedades rurais. Como geralmente, a propriedade já se encontra nas mãos da mesma família a muitas gerações, estabelece-se o desejo da permanência dos descendentes na atividade. Quando os entrevistados foram questionados sobre o desejo da permanência de seus filhos na agricultura, $75,7 \%$ afirmaram que gostariam que seus filhos continuassem na agricultura e que mantivessem a produção na propriedade da família.

Nas gerações passadas, predominava o estímulo à permanência dos filhos na agricultura. Nesta pesquisa, identificou-se que $60,9 \%$ dos produtores motivam seus filhos a permanecerem na atividade, e $26,1 \%$ não manifestam opinião para não influenciar as decisões dos filhos. O que chama a atenção é que $13 \%$ dos produtores afirmam que procuram não motivar os filhos a continuar na atividade, demostrando a total insatisfação com os rumos da agricultura na atualidade (Figura 02).

Mesmo que muitos dos filhos de agricultores demonstrem desejo de permanecerem na atividade, acabam desistindo devido aos diversos obstáculos enfrentados na atividade, principalmente, a falta de capital para investimentos necessários e a constante exigência para a modernização que o setor enfrenta, além é claro, do difícil acesso a novas áreas, devido aos altos custos para a compra de terras na atualidade.

Figura 02: Incentivo dos pais à permanência dos filhos na atividade agrícola.

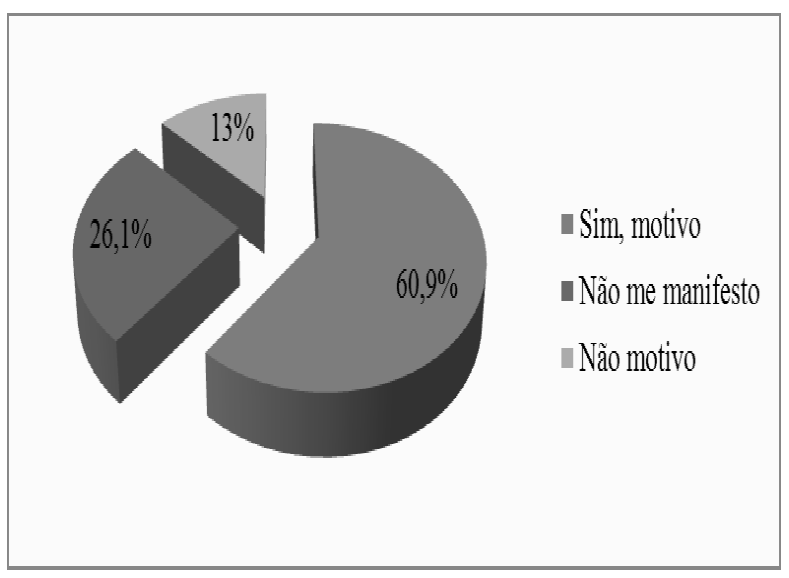

Fonte: Dados da pesquisa (2012).

A baixa remuneração da agricultura é motivo de expulsão e fator de esvaziamento do meio rural. Evidente que o porte econômico do estabelecimento pode definir ou não a presença de um sucessor. Entretanto, diferente dos assalariados, a posse de uma propriedade, mesmo de pequeno porte, permite à família viver, ou pelo menos sobreviver.

A sucessão na propriedade rural ocorre de forma lenta e gradual, e depende fundamentalmente do entendimento entre o sucessor (ou sucessores) e os que estão sendo sucedidos (neste caso, os pais) e, normalmente se dá por meio de um processo bastante 
complexo, problemático, doloroso e muitas vezes infrutífero.

Nem sempre os filhos desejam seguir na atividade agropecuária dos pais, que embora desejassem que algum filho (a) continuasse a tradição familiar de produzir na terra, acabam por desestimular os mesmos e, sem querer, acabam por provocar a evasão do campo resultando na diminuição do número de jovens que permanecem na zona rural.

A população residente no campo diminuiu em número e se elevou a faixa etária (IBGE, 2010), mas a produção agropecuária catarinense e brasileira aumenta ano após ano (CEPA, 2011), graças à melhoria nas tecnologias de produção, no nível de ensino e na automatização produtiva.

O setor primário do Oeste catarinense precisa de recursos humanos, trabalhando, produzindo, gerando riquezas e fundamentalmente, a atual geração preparando as próximas gerações para continuar a produção agrícola.

Não existe uma receita pronta para o sucesso no processo sucessório nas propriedades rurais, mas alguns aspectos são primordiais: os jovens ficam no campo e sucedem os pais na propriedade rural quando, além do gosto pela agricultura, associam um maior nível educacional ao aumento real de renda agrícola e, isto então, viabiliza um aumento da produtividade conquistada pela mecanização da produção, aumento na utilização de tecnologias e consequente, melhora dos lucros reais na produção agropecuária (STROPASOLAS, 2011).

Se o jovem percebe que a produção agrícola lhe proporcionará renda suficiente para sua manutenção, e que o fato de ficar no campo não prejudicará sua formação intelectual, isto acaba por facilitar a sua permanência na área rural (STROPASOLAS, 2011). Quando os pais recebem orientação sobre como abordar o tema sucessão com seus filhos percebe-se uma redução no êxodo rural, visto que, muitas vezes os pais desejam que seus filhos fiquem na terra, mas não conseguem demonstrar isso de forma efetiva.

\section{CONCLUSÕES}

A produção agrícola do Oeste de Santa Catarina tem predomínio de propriedades com características da agricultura familiar, ou seja, pequenas propriedades com mão-de-obra familiar e tendo como principal atividade, a produção de leite.

Os produtores sentem-se satisfeitos com a atividade agrícola, mesmo tendo que enfrentar as dificuldades inerentes à atividade e sabendo que a atividade não está entre as mais lucrativas. A maioria dos produtores almeja que seus filhos sigam com a atividade agrícola na propriedade, preservando e tornando-a cada vez mais produtiva e rentável para a família.

$\mathrm{Na}$ atualidade, vem ocorrendo uma redução no percentual de propriedades rurais 
que possuem sucessores interessados em continuar na atividade, e como possível causa, pode se apontar a baixa remuneração como o principal motivo pela não permanência dos jovens na agricultura. Outro fator que auxilia na redução de população rural baseia-se na falta de valorização e reconhecimento por parte da população urbana, dos governos e das empresas privadas, da importância da atividade agrícola para a produção de alimentos e outros produtos primários para a economia da região Oeste, bem como em nível estadual e nacional.

A busca por uma vida mais estável, com salários fixos, direitos trabalhistas (registro em carteira, $13^{\circ}$ salário, férias) e com descanso nos finais de semana, que teoricamente proporcionam uma vida mais prazerosa $\mathrm{e}$ atrativa, é outro fator que faz os jovens abandonarem o meio rural.

Os jovens que permanecem na atividade agrícola, geralmente são filhos de produtores rurais com maior poder aquisitivo, que conseguem garantir uma vida futura com mais qualidade, investimento em tecnologias produtivas e viabilizando a divisão das atividades com funcionários contratados ou em regime de parceria.

Diante disto, é importante que o poder público associado à iniciativa privada estabeleça programas de incentivo ao agricultor familiar, que condigam com as peculiaridades das diferentes regiões, e que sejam capazes de despertar o interesse dos jovens para com a atividade agrícola, e permitindo que estes percebam que seu esforço com o trabalho rural, pode e deve ser valorizado.

\section{REFERENCIAS}

ABRAMOVAY, R. et al. Agricultura familiar e sucessão profissional: novos desafios. Oeste de Santa Catarina, 2000.

ABRAMOVAY, R. (Coord.). Os impasses sociais da sucessão hereditária na agricultura familiar. Florianópolis: Epagri, Brasília: Nead/ Ministério do Desenvolvimento Agrário, 2001.

AHLERT, L. A sucessão das atividades na agricultura familiar. $47^{\circ}$ Congresso Sociedade Brasileira de Economia Administração e Sociologia Rural. Anais... Porto Alegre, 2009.

ALVES, P. A.; MATTEI, L. F. Migrações no oeste catarinense: história e elementos explicativos. XV Encontro Nacional de Estudos Populacionais, ABEP, Anais... Caxambú- MG - Brasil, 2006.

BIANCHI, J.; ORLOWSKI, R. F. A pluriatividade como estratégica de sobrevivência na agricultura familiar: um estudo de caso aplicado no município de Chapecó (SC). Disponível:

www.apec.unesc.net/...Economia\%20Rural\%20 e\%20Agricultura\%20. Acesso em: 08 mar. 2013.

CARVALHO, V. R. F. Sucessão da atividade na pequena propriedade rural na perspectiva da família e de gênero. XLV Congresso da Sociedade Brasileira de Economia, Administração e Sociologia Rural. Anais... Londrina - PR, 2007.

CEPA - Centro de Socioeconômica e Planejamento Agrícola - Epagri/Cepa. Síntese Anual da Agricultura de Santa Catarina 2009-2010. 2011. Disponível em: http://cepa. epagri.sc.gov.br/Publicacoes/Sintese_2010/sint 
ese\%202010_inteira.pdf. Acesso em: 03 fev. de 2013.

COSTA, E. O. Qualidade do leite: Contagem de células somáticas e resíduos de antibióticos. In SIMPÓSIO DE BOVINICULTURA DE LEITE, 2003, Chapecó. Anais... Chapecó: Núcleo Oeste de Médicos Veterinários, 2003. p.70-84.

ELY, E. E. Sucessão Rural: o futuro da propriedade em jogo. Disponível em: http://www.ruralnews.com.br. Acesso em: 20 abr. 2013.

FERRARI, D. L. Agricultura familiar, trabalho e desenvolvimento no Oeste de Santa Catarina. Campinas: Unicamp, 2003. 190 p. (Dissertação de mestrado Unicamp/Instituto de Economia).

HAGUETTE, T.M. Metodologias qualitativas na sociologia. Petrópolis: Vozes, 1990. 245 p.

IBGE. Censo 2010. 2010. Disponível em: http://www.censo2010.ibge.gov.br/. Acesso em: 03 fev. 2013.

JUCHEM, D. M.; BOSCARIN, P.; CÉSPEDES, E. A. H. Principais Problemas Enfrentados na Hora da Sucessão na Propriedade Rural: evidências empíricas. Passo Fundo - RS, 2006.

LEONE, N. M. de G. A sucessão não é um tabu para os dirigentes da P.M.E. XV ENANPAD. Anais... Belo Horizonte, v.7, p.243-257. 1991.

MARQUES, F. C.; MELLO, M. A. Produção de Novidades: 'desvios' da agricultura familiar no Oeste de Santa Catarina. $47^{\circ}$ Congresso Sociedade Brasileira e Economia, Administração e Sociologia Rural. Anais... Porto Alegre, 2009.

MARTINS, I. G. S et al. Empresas familiares brasileiras: perfil e perspectivas. São Paulo: Negócio Editora, 1999.
MELLO, M. A. Transformações sociais recentes no espaço rural do oeste de Santa Catarina: migração, sucessão e celibato. XLIV Congresso da Sociedade Brasileira de Economia e Sociologia Rural. Anais... Fortaleza, 2006.

MELLO, M. A.; FERRARI, D. L. A base agrícola do Oeste Catarinense, a importância e o perfil da atividade leiteira. In: TESTA, V. M. (Org.). A escolha da trajetória da produção de leite como estratégia de desenvolvimento do Oeste Catarinense. Florianópolis, SC: SAR, 2003. 130 p.

MENDONÇA, K. F. C.; RIBEIRO, A. E. M.; GALIZONI, F. M. Sucessão na agricultura familiar: estudo de caso sobre o destino dos jovens do alto Jequitinhonha, MG. XVI Encontro Nacional de Estudos Populacionais. Anais... Caxambu- MG, 2008.

MDA. Agricultura Familiar: Primeiros Resultados, Ministério do Desenvolvimento Agrário, Brasília-DF, 2009.

MONTOYA, M. A.; FINAMORE, E. B. Características dos produtores de leite do RS: uma análise a partir do Corede Nordeste.

Indicadores Econômicos FEE. v. 37, n. 4, p. 213-224. Porto Alegre, 2010.

MULLER, E. E. Qualidade do leite, células somáticas e prevenção da mastite. Simpósio sobre Sustentabilidade da Pecuária Leiteira na Região Sul do Brasil, Anais..., p.206-217. Toledo - PR, 2002.

OLIVEIRA, C. A. F. D.; FONSECA, L. F. L. D.; GERMANO, P. M. L. Aspectos relacionados à produção, que influenciam a qualidade do leite. Higiene Alimentar, v.13, n.62, p.10-16, jun. 1999.

PLEIN, C. A formação da agricultura familiar no oeste de Santa Catarina: o caso das colônias porto Feliz e Porto Novo. Revista Faz Ciência, v.07, n.01, pp. 79-102, 2005. 
SCHNEIDER, S. As novas formas sociais do trabalho no meio rural: a pluriatividade e as atividades rurais não-agrícolas. Revista Redes, Santa Cruz do Sul - RS, v. 9, n. 3, p. 75-109, 2005.

SILVESTRO, M. L.; et al. Os impasses sociais da sucessão hereditária na agricultura familiar. Florianópolis: Brasília: Epagri: NEAD/Ministério do Desenvolvimento Agrário, 2001, 120p.

STROPASOLAS, V. L. Os desafios da sucessão geracional na agricultura familiar.

Agriculturas, Rio de Janeiro, v. 8, n. 1, 2011.

THIOLLENT, M. Metodologia da pesquisaação. São Paulo: Cortez, 1996. 108 p.

WEISHEIMER, N. Juventudes rurais: mapa de estudos recentes. Brasília: Ministério do Desenvolvimento Agrário, 2005. 